\title{
A Global Empirical Model of the Ion Temperature in the Ionosphere for the International Reference Ionosphere
}

\author{
Vladimír Truhlík ${ }^{1, *(1)}$, Dieter Bilitza ${ }^{2,3}$, Dmytro Kotov $^{4}$, Maryna Shulha ${ }^{4}$ and Ludmila Tř́sková ${ }^{1}$ \\ 1 Institute of Atmospheric Physics of the Czech Academy of Sciences, 14100 Praha 4, Czech Republic; \\ 1tr@ufa.cas.cz \\ 2 Department of Physics and Astronomy, George Mason University, Fairfax, VA 22030, USA; dbilitza@gmu.edu \\ 3 Heliospheric Laboratory, NASA Goddard Space Flight Center, Greenbelt, MD 20771, USA \\ 4 Institute of Ionosphere, 61001 Kharkiv, Ukraine; dmitrykotoff@gmail.com (D.K.); \\ marina.shulga23@gmail.com (M.S.) \\ * Correspondence: vtr@ufa.cas.cz
}

Citation: Truhlík, V.; Bilitza, D.; Kotov, D.; Shulha, M.; Třísková, L. A Global Empirical Model of the Ion Temperature in the Ionosphere for the International Reference Ionosphere. Atmosphere 2021, 12, 1081. https:// doi.org/10.3390/atmos12081081

Academic Editors:

Christine Amory-Mazaudier and Sergey Pulinets

Received: 4 August 2021

Accepted: 17 August 2021

Published: 23 August 2021

Publisher's Note: MDPI stays neutral with regard to jurisdictional claims in published maps and institutional affiliations.

Copyright: (C) 2021 by the authors Licensee MDPI, Basel, Switzerland. This article is an open access article distributed under the terms and conditions of the Creative Commons Attribution (CC BY) license (https:/ / creativecommons.org/licenses/by/ $4.0 /)$.

\begin{abstract}
This study presents a suggestion for improvement of the ion temperature (Ti) model in the International Reference Ionosphere (IRI). We have re-examined ion temperature data (primarily available from NASA's Space Physics Data Facility (SPDF)from older satellites and combined them with newly available data from the Defense Meteorological Satellite Program (DMSP), the Communication Navigation Outage Forecasting System (C/NOFS), and from the recently launched Ionospheric Connection Explorer (ICON). We have compiled these data into a unified database comprising in total Ti data from 18 satellites. By comparisons with long term records of ion temperature from the three incoherent scatter radars (ISRs) (Jicamarca, Arecibo, and Millstone Hill), it was found that an intercalibration is needed to achieve consistency with the ISR data and among individual satellite data sets. This database with thus corrected data has been used for the development of a new global empirical model of Ti with inclusion of solar activity variation. This solar activity dependence is represented by an additive correction term to the Ti global pattern. Due to the limited data coverage at altitudes above $1000 \mathrm{~km}$, the altitude range described by the model ranges from $350 \mathrm{~km}$ to $850 \mathrm{~km}$ covering only the region where generally $\mathrm{Ti}$ is higher than the neutral temperature (Tn) and lower than the electron temperature (Te). This approach is consistent with the current description of $\mathrm{Ti}$ in the IRI model. However, instead of one anchor point at $430 \mathrm{~km}$ altitude as in the current IRI, our approach includes anchor points at 350, 430,600, and $850 \mathrm{~km}$. At altitudes above $850 \mathrm{~km}$ Ti is merged using a gradient derived from the model at 600 and $850 \mathrm{~km}$, with the electron temperature described by the IRI-2016/TBT-2012 option. Comparisons with the ISR data (Jicamarca, Arecibo, Millstone Hill, and Kharkiv) for high and low solar activity and equinox show that the proposed Ti model captures local time variation of Ti at different altitudes and latitudes better than the current IRI-2016 Ti model.
\end{abstract}

Keywords: ion temperature; topside ionosphere; solar activity; empirical model; international reference ionosphere

\section{Introduction}

The research on the temperatures of charged thermal particles, which is crucial for understanding thermal processes in the ionosphere and adjacent regions, has been conducted since the 1960s. As the understanding of these processes advanced, it was found that the ionospheric plasma is not in thermal equilibrium and, in general, the temperatures of the electrons (Te) and ions (Ti) are different [1]. Together with theoretical and experimental studies, the need for an empirical description of these temperatures emerged. The empirical description of $\mathrm{Te}$ and $\mathrm{Ti}$ in the ionosphere, topside ionosphere and plasmasphere is one of the tasks of the IRI COSPAR/URSI working group. The main efforts have been devoted to the modelling of the electron temperature (e.g., [2-5]), because the excess energy from the photoionization of neutral particles in the upper atmosphere by the solar EUV (Extreme 
ultraviolet) photons is primarily received by the electrons and then transferred to the ions and from them to the neutral particles, e.g., Schunk and Nagy [6]. Another reason for focusing on global empirical modeling of the electron temperature rather than the ion temperature was the relative simplicity of Te measurements with Langmuir probes [7] while ion temperature measurements required the more involved the retarding potential analyzers (RPA) technique [8] and more recently ion imagers [9]. As a result, the amount of data collected for the electron temperature far exceeded the amount of reliable ion temperature measurements [10].

The general formulation of the thermal balance equations includes temperatures related to different ion species, and thus in general different ions do not have the same temperature [11], which has also been pointed out experimentally in the case of the temperatures of light ions such as $\mathrm{H}^{+}$versus heavier ones such as $\mathrm{O}^{+}$[12]. Our study is focused on the $\mathrm{O}^{+}$temperature since $\mathrm{O}^{+}$is the predominant ion or constitutes a substantial fraction in the altitude range that is of interest for this study.

For the calculation of the ion temperature, the IRI model [13] employs an approach that is described in [14] (pp. 68-69) and was recently reviewed and assessed by Pignalberi et al. [15] with the help of the Millstone Hill incoherent scatter radar (ISR) data. The essence of this approach is that the model uses Ti RPA data from the AEROS-A satellite at an altitude of $430 \mathrm{~km}$ to establish a fixed anchor point at this altitude. Ti below this altitude is then extrapolated by searching for a tangential point on the neutral temperature (Tn) profile from the NRLMSISE-00 model [16]. Above $430 \mathrm{~km}$ altitude, an extrapolation is performed using the average gradient for day and night estimated using ISR data (Arecibo and Millstone Hill). The constraint $\mathrm{Tn} \leq \mathrm{Ti} \leq \mathrm{Te}$ then applies in the whole range of altitudes. However, since the construction of this Ti model for IRI, an incomparably larger amount of Ti data has been accumulated and has become available through NASA's Space Physics Data Facility (SPDF: https://spdf.gsfc.nasa.gov/pub/data, accessed on 7 November 2019) and through other data centers. Still, not all data are available, but the much more favorable policy of many universities and research institutions in sharing new data compared to the past allows more data to be collected for model construction. This has provided us with a large amount of data that we believe is suitable for revising the IRI Timodel and producing a new version, with the inclusion of more anchor points, better resolution in latitude and local time, and the explicit representation of variation with solar activity. Furthermore, we use the large volume of ISR data, that are publicly available thanks to the Open Madrigal Initiative (https: / / openmadrigal.org, accessed on 13 May 2020), for correction or intercalibration of the satellite data. Our study is a good example of the synergy obtained by combining data from different sources. Nevertheless, the model still has a number of limitations, and in the future it is necessary to obtain additional data or to engage other modelling techniques and methods in order to construct a model for the whole range of heights, including the incorporation of all relevant geophysical and solar parameters.

The paper is organized as follows. In Section 2, we describe our database, its verification, correction and intercalibration using ISR data. In Section 3, we present the construction of the proposed Ti model. Then, in Section 4, we describe how the altitude profiles were constructed and how they are connected to Tn and Te. In Section 5 we show the results of the model, and in Section 6 we compare with the ISR data. Finally, in Section 7 we discuss the findings and conclude the paper.

\section{Data}

We have built a database that comprises of as much available Ti data from in situ satellite measurements as possible. This database covers a time period of more than fifty years, i.e., almost five solar cycles. Table 1 lists the satellites and experiments included in the database and their corresponding time intervals, altitude, latitude, and solar local time (SLT) ranges, and the average PF10.7 index. All included experiments were based on the 
RPA technique. This method enables one to deduce values for several important parameters of the ionospheric plasma with the ion temperature being one of them (e.g., [8,17]).

Table 1. A list of the satellites and experiments included in the database and their corresponding time intervals, altitude, latitude, and solar local time (SLT) ranges, and the average PF10.7 index.

\begin{tabular}{|c|c|c|c|c|c|c|}
\hline No & $\begin{array}{c}\text { Satellite } \\
\text { (Experiment) }\end{array}$ & $\begin{array}{c}\text { Time Period (Data } \\
\text { Avail) }\end{array}$ & Altitude [km] & Latitude [deg] & SLT [h] & $\overline{P F 10.7}$ \\
\hline 1 & OGO-6 (RPA) & 12. 1969-4. 1971 & 390-1090 & $-82 \ldots+82$ & $0-24$ & 155 \\
\hline 2 & AEROS A (RPA) & 1. $1973-8.1973$ & $200-870$ & $-83 . .+83$ & 3,15 fixed & 98 \\
\hline 3 & AEROS B (RPA) & 7. 1974-9. 1975 & $140-880$ & $-83 . .+83$ & 4,16 fixed & 86 \\
\hline 4 & AE-C (RPA) & 12. $1973-12.1978$ & 135-2010 & $-68 \ldots+68$ & $0-24$ & 86 \\
\hline 5 & AE-D (RPA) & 10. 1975-1. 1976 & $140-1980$ & $-89 . .+89$ & $0-24$ & 76 \\
\hline 6 & AE-E (RPA) & 12. $1975-5.1981$ & $140-1580$ & $-20 . .+20$ & $0-24$ & 129 \\
\hline 7 & DE-2 (RPA) & 8. $1981-2.1983$ & $200-1020$ & $-90 \ldots+90$ & $0-24$ & 180 \\
\hline 8 & San Marco 5 (RPA) & 4. $1988-12.1988$ & $170-590$ & $-3 . .+3$ & $0-24$ & 151 \\
\hline 9 & IK24 (RPA) & 10. 1989-2. 1993 & $500-2525$ & $-83 \ldots+84$ & $0-24$ & 195 \\
\hline 10 & DMSP F11 (RPA) & 1. $1992-5.2000$ & $840-890$ & $-81 \ldots+87$ & 6,18 fixed & 119 \\
\hline 11 & DMSP F12 (RPA) & 1. 1996-6. 2002 & $840-890$ & $-82 \ldots+89$ & 9,21 fixed & 132 \\
\hline 12 & DMSP F13 (RPA) & 3. 1995-12. 2005 & $840-880$ & $-81 \ldots+82$ & 6,18 fixed & 131 \\
\hline 13 & DMSP F14 (RPA) & 4. 1997-7. 2003 & $840-885$ & $-81 \ldots+82$ & 9, 21 fixed & 121 \\
\hline 14 & DMSP F15 (RPA) & 12. $1999-12.2017$ & $830-880$ & $-86 . .+86$ & $9.5,21.5$ fixed & 116 \\
\hline 15 & SROSS C2 (RPA) & 1. $1995-12.2000$ & $380-620$ & $-40 \ldots+45$ & $0-24$ & 110 \\
\hline 16 & ROCSAT-1(RPA) & 3. 1999-6. 2004 & $560-665$ & $-35 \ldots+35$ & $0-24$ & 160 \\
\hline 17 & C/NOFS (RPA) & 8. 2008-11. 2015 & $260-855$ & $-13 . .+13$ & $0-24$ & 106 \\
\hline 18 & ICON IVM (RPA) & 10. 2019-6. 2020 & $575-610$ & $-27 . .27$ & $0-24$ & 70 \\
\hline
\end{tabular}

Relevant references to the experiments onboard individual satellites: (1) Hanson et al. [18]; (2, 3) Spenner and Dumbs [19]; (4-6) Hanson et al. [20]; (7) Hanson et al. [21]; (8) Broglio et al. [22]; (9) Afonin and Smirnova [23]; (10-14) Rich [24]; (15) Garg et al. [25]; Borgohain and Bhuyan [26] (16) Su et al. [27]; Chao et al. [28]; (17) de La Beaujardière [29]; (18) Heelis et al. [30].

The database consists of binary records that contain information on the measured ion temperature, the time (universal time-UT) of the measurement and also geographic and geomagnetic coordinates, as well as geophysical and solar parameters. In general, the experiments listed in Table 1 used different sampling rates, which in many cases are too high for our purpose of studying global distribution of the ion temperature, and therefore we have resampled the time resolution of all data to $100 \mathrm{~s}$. These $100 \mathrm{~s}$ samples represent the medians of all Ti measurements within a $100 \mathrm{~s}$ interval. This sampling period is the same as the one we used earlier for our electron temperature database [31]. We would like to note that the $100 \mathrm{~s}$ interval for polar-orbiting satellites corresponds to a resolution of approximately 7 degrees in latitude and for equatorial satellites to a resolution of approximately $30 \mathrm{~min}$ in local time, which is significantly better than the resolution of the model presented in this paper. The advantage of this reduced resolution is a significant reduction in the volume of data in our database and therefore in the demands on disk storage capacity, computer memory, power and time. Nevertheless, the total number of data samples in our database is approximately 13 million.

Figure 1 shows the year-altitude coverage of data in the database and the corresponding solar flux (PF10.7 index [32]).

From Table 1 and Figure 1, it is apparent that the coverage in UT time (years), altitude, latitude, and other important parameters for description of the ion temperature is uneven. On the other hand, a unique advantage of satellite data is that it can provide information on global characteristics of the ion temperature, unlike ground-based techniques such as incoherent scatter radars (ISRs), which only provide information near specific geographic locations. 


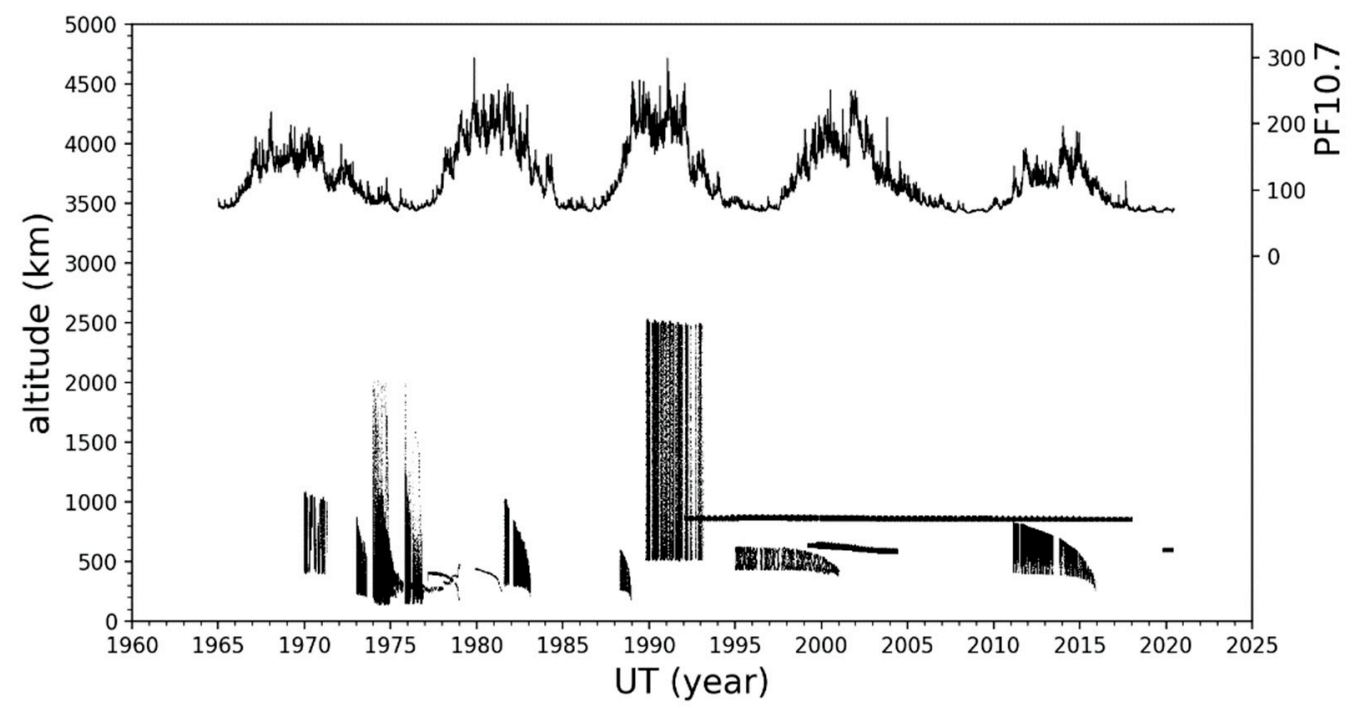

Figure 1. Year-altitude coverage of data in the database for individual satellite missions and corresponding 81-day running mean of the F10.7 index.

\subsection{Quality Data Assessment and Data Intercalibration}

As the first step, we checked the data from each satellite separately. If the dataset contained a quality flag (DMSP, C/NOFS, ICON), we selected only those values that were marked with the best quality flag. Based on the Ti plots, we excluded values that could be considered outliers, i.e., unphysically too high (above many thousands of K) or low (below a few hundred K) values for the corresponding satellite altitudes. Especially for older data obtained from the archives this could be due to errors in the satellite position. Next, we checked consistency of the data in the database, i.e., whether the individual data sets for equivalent conditions (given by geomagnetic latitude, local time, altitude, season and solar activity) give consistent, i.e., sufficiently close values. We produced plots of the ion temperature for typical conditions (day, night, geomagnetic equator, low, mid and high latitudes, low, mid and high solar activity, equinox, solstice, etc.) in which data points from each satellite were color-coded. We found that there are remarkable differences between some of the datasets. This is not surprising, since these experiments were developed by different manufacturers and experimenters, using sensors and electronics of different designs and applying different data analysis techniques. Therefore, intercalibration is necessary when combining different data sets.

Thus, it has to be decided which dataset to take as an accurate baseline and to find a correction factor for the others to achieve consistency of all datasets in the database that would be suitable for development of the global models. To address this task, we took advantage of the availability of long-term ion temperature records from three ISRs, the equatorial ISR at Jicamarca $\left(11.95^{\circ} \mathrm{S}, 76.87^{\circ} \mathrm{W}\right)$, the lower mid-latitude ISR at Arecibo $\left(18.35^{\circ} \mathrm{N}, 66.75^{\circ} \mathrm{W}\right)$, and the higher mid-latitude ISR at Millstone Hill $\left(42.62^{\circ} \mathrm{N}, 71.48^{\circ} \mathrm{W}\right)$. These ISRs have provided data for decades, and their measurements of plasma parameters can be considered reliable and even standard. We used ISR data from an altitude range of $\sim 300-650 \mathrm{~km}$. Above an altitude of $\sim 650 \mathrm{~km}$, not all ISRs provide Ti values; moreover, these data are often affected by a high level of noise and thus can be burdened with significant errors. This fact makes a direct comparison between DMSP (altitude about $850 \mathrm{~km}$ ) and ISR difficult. For other satellites included in our database (Table 1) at least part of the orbit can fit into this altitude range (Figure 1). Since the available ISR data sets are very inhomogeneous with respect to the time axis (UT), it is almost impossible to find a sufficient number of satellite flybys when satellite and ISR data are available at the same time. This is especially limiting in the case of older satellite missions where the number of data points is relatively small. Therefore, we decided to make a comparison and determine correction factors for equivalent conditions, i.e., to compare medians from multiple Ti 
samples for a given interval of altitude, geomagnetic latitude, height, solar activity, and season, regardless of the UT for which the measurements were made.

The ISR Ti datasets from each ISR were obtained from http:/ / cedar.openmadrigal.org (accessed on 13 May 2020). Employing scripts created using the Openmadrigal site, we downloaded all available data in the $300-660 \mathrm{~km}$ altitude range in ASCII format. The downloaded parameters were as follows: "YEAR, MONTH, DAY, SLT, UT, GDALT, PL, TI, DTI", which means year, month, day, solar local time in hours, universal time (hours), geodetic altitude, pulse length, ion temperature and error in ion temperature. More information about the individual ISRs (Jicamarca, Arecibo, Millstone Hill) can be found at http:/ / cedar.openmadrigal.org (accessed on 13 May 2020). In further processing, we filtered the data to exclude unphysical values or values with large error as follows: the ion temperature data lower than $400 \mathrm{~K}$ and higher than $6000 \mathrm{~K}$ were excluded and only values with DTI/TI $<0.25$ were used. Table 2 shows the number of Ti values that remained after this filtering process together with the time period for which data are available, the geographical coordinates (latitude, longitude), and the invdip coordinate [33] and its change over the time period due to the change of the geomagnetic field.

Table 2. Three ISRs and available Ti data.

\begin{tabular}{cccccc}
\hline ISR & $\begin{array}{c}\text { Time Period } \\
\text { (Data Availability) }\end{array}$ & $\begin{array}{c}\text { Number of } \\
\text { Ti Samples }\end{array}$ & Latitude (deg) & Longitude (deg) & Invdip (deg) \\
\hline Jicamarca & $10.1996-2.2020$ & 24,266 & -11.95 & -76.87 & $0.0 \pm 0.6$ \\
Arecibo & $4.1982-3.2015$ & 68,088 & 18.35 & -66.75 & $28.2 \pm 2.2$ \\
Millstone Hill & 2. 1976-1. 2020 & 526,216 & 42.62 & 71.48 & $52.8 \pm 2.1$ \\
\hline
\end{tabular}

To compare satellite (Table 1) and ISR (Table 2) data we binned all Ti data from each satellite at the $\pm 5^{\circ}$ invdip range centered at the position of each ISR $\left(0^{\circ}, 28.2^{\circ}\right.$, and $\left.52.8^{\circ}\right)$ (we consider the effect of longitude as a third-order effect), as well as we binned all $\mathrm{Ti}$ data from each ISR according to the parameters that have a first-order and second-order influence as follows:

- Four seasons (centered at March 21, June 21, September 23, and December 21 and extending \pm 30 days);

- Six altitudes (centered at $350 \mathrm{~km}, 400 \mathrm{~km}, 450 \mathrm{~km}, 500 \mathrm{~km}, 550 \mathrm{~km}, 600 \mathrm{~km}$ and extending $\pm 10 \%$ above and below of the given altitude);

- $\quad$ Twenty-four magnetic local times (MLT) (centred at $0.5 \mathrm{~h}, 1 \mathrm{~h}, 1.5 \mathrm{~h}, \ldots, 23.5 \mathrm{~h}$ and within $\pm 0.5 \mathrm{~h})$;

- $\quad$ Twelve levels of solar activity (PF10.7 centred at 72.5, 87.5, ..., 237.5 and within \pm 7.5 s.f.u.).

We evaluated the median of all Ti values in each bin. Thus, for each satellite from Table 1, we obtained three four-dimensional arrays each with a total of 6912 elements. For each ISR we obtained one such four-dimensional array. For many of these elements there was no measurement and therefore such elements had zero value. The next step was to make scatterplots of Ti-ISR vs. Ti-satellite for each satellite separately (Figure 2). Zero values were not taken into account. For the satellites for which the scatterplots pertaining to each ISR invdip bin showed a too low number of points or reasonably small differences, the data from all three ISR invdip bins were combined and a single dependence was determined by a least squares fitting. Otherwise, the dependencies were determined separately and a linear interpolation was then used to obtain the correction for all latitudes. In the case of the DMSP satellites, the comparison with the ISR is difficult due to their high orbit altitude $(\sim 840 \mathrm{~km})$; neither the Jicamarca nor the Arecibo ISR provide data for such altitudes at least in normal mode of operation. We made a comparison with the already corrected data from the elliptically orbiting DE-2, OGO-6, and C/NOFS satellites for which we applied the correction using the procedure on their low altitude part of orbit (Table 3, line 1, 7, and 17). The correction was done for all DMSP satellites from Table 1 together, since we believe 
that due to the similarity of the experiment and the design of the satellites, the data are consistent with each other. Table 3 summarizes the dependencies (corrections) obtained for each satellite.

Table 3. Correction formulas proposed for the Ti values from the experiments included in our database.

\begin{tabular}{|c|c|c|}
\hline No & Satellite (Experiment) & Correction Formula \\
\hline 1 & OGO-6 (RPA) & \multirow{11}{*}{$\begin{array}{c}T i_{\text {corr }}=1.015 \mathrm{Ti}-2 \\
T i_{\text {corr }}=0.765 \mathrm{Ti}+118 \\
T i_{\text {corr_day }}=0.803 \mathrm{Ti}+81 \\
T i_{\text {corr_night }}=0.166 \mathrm{Ti}+642 \\
T i_{\text {corr }}=-0.0000865 \mathrm{Ti} i^{2}+0.868 \mathrm{Ti}+175 \\
\text { No coincidences-excluded } \\
T i_{\text {corr }}=0.936 \mathrm{Ti}-22 \\
T i_{\text {corr }}=0.848 \mathrm{Ti}+107 \\
\text { Ti } i_{\text {corr }}=1.0 \mathrm{Ti}+21 \\
\text { Not enough coincidences-excluded }\end{array}$} \\
\hline 2 & AEROS A (RPA) & \\
\hline 3 & AEROS B (RPA) & \\
\hline 4 & AE-C (RPA) & \\
\hline 5 & AE-D (RPA) & \\
\hline 6 & AE-E (RPA) & \\
\hline 7 & DE-2 (RPA) & \\
\hline 8 & San Marco 5 (RPA) & \\
\hline 9 & IK24 (RPA) & \\
\hline 10 & DMSP F11 (RPA) & \\
\hline 11 & DMSP F12 (RPA) & \\
\hline 12 & DMSP F13 (RPA) & \multirow[t]{3}{*}{$T i_{\text {corr }}=0.844 T i+82$} \\
\hline 13 & DMSP F14 (RPA) & \\
\hline 14 & DMSP F15 (RPA) & \\
\hline 15 & SROSS C2 (RPA) & \multirow{4}{*}{$\begin{array}{c}T i_{\text {corr }}=0.000189 T i^{2}+0.396 T i+386 \\
T i_{\text {corr } \_J C}=0.785 T i+281 \\
T i_{\text {corr_AR }}=0.955 T i+112 \\
T i_{\text {corr }} J I C=0.641 T i+350 \\
T i_{\text {corr } A R}=0.543 T i+459 \\
T i_{\text {corr }}=0.648 T i+173\end{array}$} \\
\hline 16 & ROCSAT-1(RPA) & \\
\hline 17 & C/NOFS (RPA) & \\
\hline 18 & ICON IVM (RPA) & \\
\hline
\end{tabular}

Figure 2 and Table 3 show the rather surprising result that the satellite Ti data obtained by RPA experiments tend to consistently overestimate Ti values measured by ISRs. For some missions like OGO-6 or San Marco, the agreement with ISRs is very good; however, these are missions with a rather limited data set. In the case of AE-C, the agreement with the ISR is very good for Ti values below $\sim 1200 \mathrm{~K}$, i.e., mainly in the low solar activity part of lifetime of AE-C. Similarly, Ti from DE-2 agrees well with Ti from ISR for lower ion temperature values. Unfortunately, in the case of AE-D and IK-24, we did not find any or enough values for the scatterplot to obtain a reliable correction, and therefore we had to exclude them from the database for the global model development. The ion temperature from the AEROS-A and AEROS-B satellites shows a very similar overestimation of the IRS data. Interestingly, in the case of the AEROS-B satellite, the nighttime part of the orbit shows a significantly higher overestimation than the daytime part. ROCSAT-1, which accounts for a significant fraction of the data at altitudes around $600 \mathrm{~km}$ in the database, shows generally good agreement with the ISR data, but for lower values $(\mathrm{Ti}<1300 \mathrm{~K}) \mathrm{Ti}$ from the satellite, especially at the equator, tends to underestimate the ISR data. The more recent C/NOFS satellite with an elliptical orbit, which decayed at the end of 2015, and the very latest ICON satellite with a late 2019 launch, which we included for better coverage during periods of very low solar activity, show significantly less agreement with the ISR data. We would like to emphasize that in the case of both experiments, we selected only data with the best quality flag values. Additionally, C/NOFS Ti data for PF10.7 $<95$ were completely removed because they showed a very significant overestimation. In the case of ICON, Truhlik et al. [34] proposed a correction based on equatorial data for nighttime. The new correction presented in Table 2 is based on data for the entire daytime/nighttime period. Both proposed corrections are consistent for low nighttime equatorial Ti values. As already mentioned the correction in the case of DMSP was made on the basis of comparison with already corrected satellite data. These were data sets from the following satellites with elliptical orbits: DE-2, OGO-6, and C/NOFS. Like most of the other satellites from Table 2, the DMSP Ti data require some temperature reduction, as well. The difference between the 
typical daytime measured (about $2300 \mathrm{~K}$ ) and corrected value is about $300 \mathrm{~K}$, i.e., about $13 \%$, which can be considered a relatively moderate correction. In the case of nighttime values in the equatorial region (about $1000 \mathrm{~K}$ and less) the correction is almost negligible.
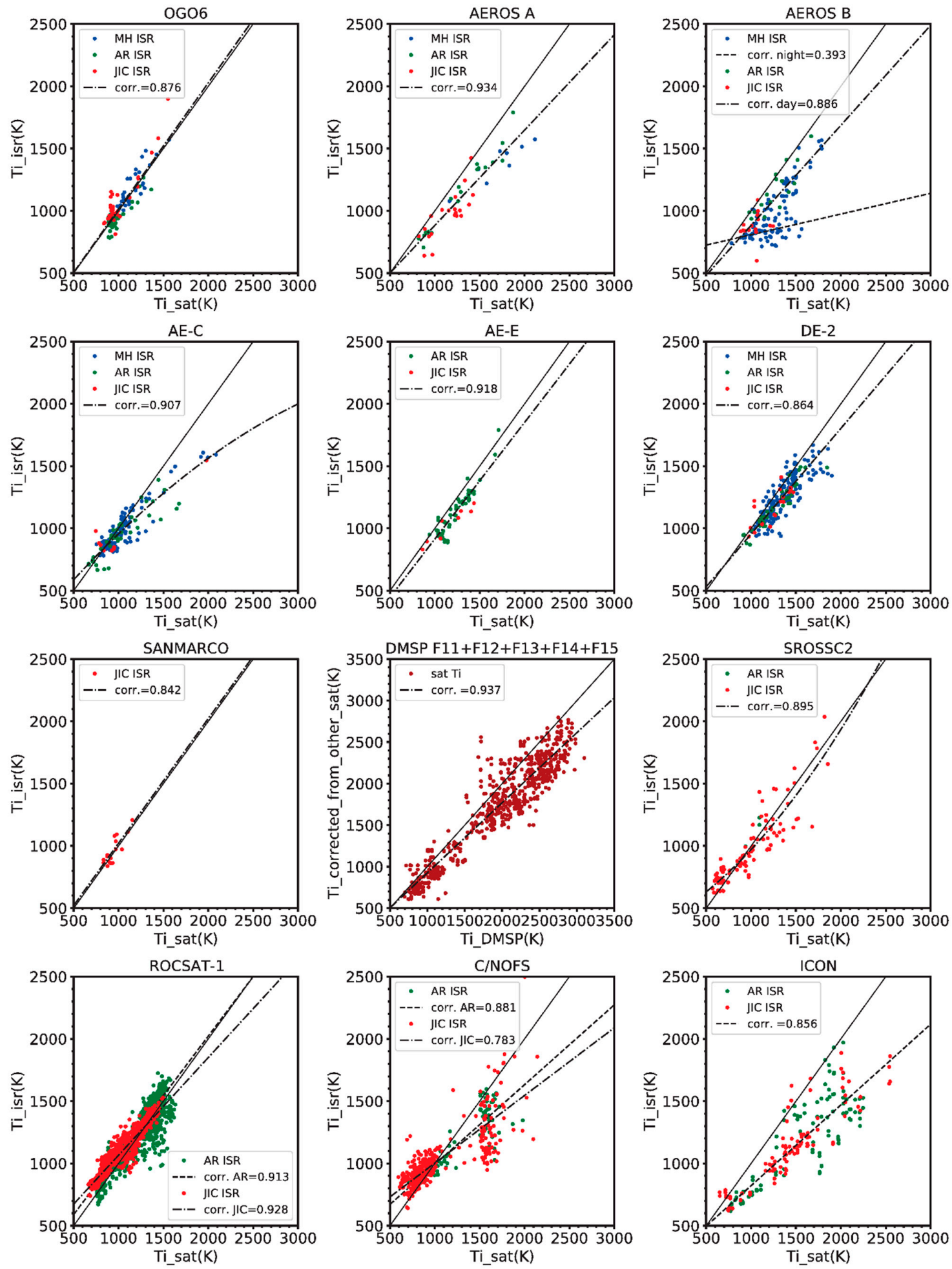

Figure 2. Scatterplots of binned Ti values from ISRs vs. binned Ti values from satellites. The bins corresponding to Jicamarca are shown by red points, Arecibo by green points, and Millstone Hill by blue points. Information on the Pearson correlation coefficient (corr.) is also included. For DMSP (brown points), the scatterplot represents a comparison with already corrected satellite data (vertical axis; "other_sat" stand for DE-2, OGO-6, and C/NOFS). Additionally, shown are the least-square fits to the data (dash-dotted and dashed line) and the line marking perfect agreement: Ti_sat = Ti_isr (solid line). 


\section{Model}

Based on the altitude distribution of the data in our database (see Figure 3) and the need to cover all important altitude regions, we selected four anchor altitudes for our model: $350,430,600$, and $850 \mathrm{~km}$. The lowest one at $350 \mathrm{~km}$ corresponds to one of the anchor points used in the IRI electron temperature model [2]. We included an anchor altitude at $430 \mathrm{~km}$, which corresponds to the anchor altitude in the current IRI ion temperature model, to allow easier comparison of both models. The upper two anchor altitudes of 600 and $850 \mathrm{~km}$ correspond to the two peaks in our histogram of available Ti data in Figure 3. These peaks are produced by the satellites ROCSAT-1, ICON and DMSP, which operate or operated in circular orbits at one of these altitudes. The IRI electron temperature model includes even higher anchor points at 1400 and $2000 \mathrm{~km} \mathrm{[2]} \mathrm{and} \mathrm{thus} \mathrm{reaching} \mathrm{the} \mathrm{lower} \mathrm{boundary} \mathrm{of}$ the plasmasphere. Figure 3 shows that our data base does not provide adequate data to build a global model at these altitudes; see the sharp decline in the data distribution above $1000 \mathrm{~km}$. However, for these altitudes, we can assume that electrons and ions are close to thermal equilibrium state $(\mathrm{Ti} \approx \mathrm{Te})$ (see Section 4$)$.

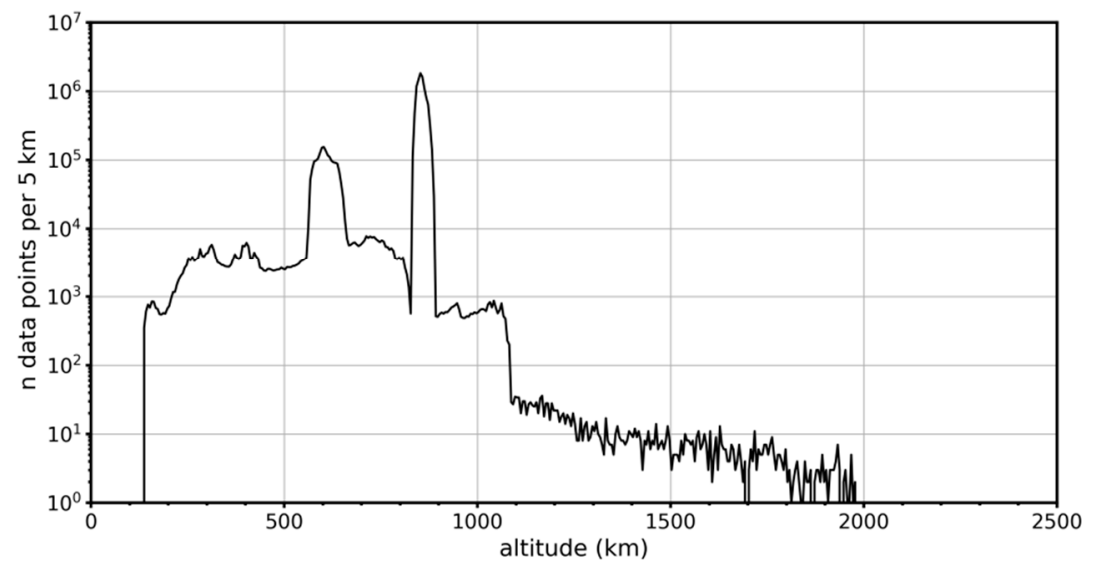

Figure 3. Histogram (number of data points in $5 \mathrm{~km}$ bins vs. altitude) of the ion temperature data in our database.

Similar to Truhlik et al. [2], we used a local time-latitude grid and modeled global variations using spherical harmonic. In the first step, we built a base Ti model. In the second step, we created a term describing the variation with solar activity. This term is based on modeling the residuals of the data from the base model. The solar activity variation term is used as an additive term to the base model.

\subsection{The Base Model}

The base model consists of submodels for individual altitude ranges and seasons. All available data were grouped by season (90 day periods centered on equinoxes and solstices) and for the following altitude ranges: $350 \pm 40 \mathrm{~km}, 430 \pm 45 \mathrm{~km}, 600 \pm 60 \mathrm{~km}$, and $850 \pm 90 \mathrm{~km}$ similar to the approach used by Truhlik et al. [2]. These height intervals were chosen based on the compromise of requiring as much data as possible for the best coverage, but at the same time such that the temperature change in this interval could be considered negligible. For equinox we have combined data from spring and autumn (90 day periods centered on 21 March and 23 September) from both hemispheres, because we consider possible hemispheric asymmetries to be an influence of the 3rd order (1st order effects are related to local time, and altitude; 2nd order to season, and solar activity; 3 rd order to longitude, hemispheric differences, and magnetic activity). For solstices we have also combined data from both hemispheres (northern hemisphere-three months periods centered on 21 June plus southern hemisphere-three months periods centered on 21 December for summer, and vice versa for winter). Magnetic local time (MLT) and latitude were chosen as the main coordinates. Longitudinal variation can be reduced to a 
less significant effect if a latitudinal coordinate is chosen that takes into account the real configuration of the geomagnetic field [3]. The latitudinal coordinate (invdip), introduced by Truhlik at al. [33], is such a coordinate and it is employed in our Ti model.

For each individual data group (height range and season) a system of associated Legendre polynomials up to the 8th order was fitted to the data:

$$
T i_{\text {base }}(\text { invdip, } M L T)=a_{0}^{0}+\sum_{l=0}^{8}\left\{a_{l}^{0} P_{l}^{0}(\cos \theta)+\sum_{m=1}^{l}\left[a_{l}^{m} \cos (m \varphi)+b_{l}^{m} \sin (m \varphi)\right] P_{l}^{m}(\cos \theta)\right\}
$$

where $P_{l}^{m}$ is associated Legendre function,

$\theta$ is invdip colatitude $(0 . . \pi)$,

$\varphi$ is magnetic local time $(0 . .2 \pi)$, and

$a_{l}^{m}$ and $b_{l}^{m}$ are coefficients.

In our selection of the maximum order of expansion, we were limited by the data coverage. A higher degree of the expansion means the need for a denser grid, in particular, the 8th degree requires at least 18 points in MLT and 9 points in invdip to guarantee coefficients fully recoverable and free of aliasing effects [35]. We solved Equation (1) by a least squares fitting. Thus, for the coefficients $a_{l}^{m}$ and $b_{l}^{m}$ we have obtained a system of linear equations with a symmetric matrix. The solution for such a system can be found using the matrix inversion method.

\subsection{The Whole Model}

For the development of the base model we ignored the solar activity dependence of $\mathrm{Ti}$ in effect averaging over solar activity. We now have to introduce a term to describe this second order variation of Ti. We propose the solar activity term $T i_{\text {solact }}$ as an additive term to the core model $\left(T i_{\text {base }}\right)$. Using the PF10.7 index as a proxy for solar activity, the whole model can be expressed as:

$$
T i_{\text {model }}(\text { invdip, } M L T, P F 10.7)=T i_{\text {base }}(\text { invdip }, M L T)+T i_{\text {solact }}(\text { invdip, } M L T, P F 10.7)
$$

To include the possibility of a nonlinear dependence of the ion temperature on solar activity, we suggest the $T i_{\text {solact }}$ (invdip, MLT, PF10.7) term in the following form:

$$
\operatorname{Ti}_{\text {solact }}\left(\text { invdip, MLT, PF10.7) }=a_{\text {lin }} \text { PF10.7 }+b_{\text {lin }}+a_{\text {qua }} \text { PF10.7 } 7^{2}+b_{\text {qua }} \text { PF10.7 }+c_{\text {qua }}\right.
$$

The term includes both a linear $\left(a_{\text {lin }} \mathrm{PF} 10.7+b_{\text {lin }}\right)$ and a quadratic part $\left(a_{q u a} \mathrm{PF} 10.7^{2}+\right.$ $\left.b_{q u a} \mathrm{PF} 10.7+c_{q u a}\right)$. This form can be obtained from the first three terms of the Taylor series, where corresponding first and second derivatives are included in the coefficients. This approach follows from the requirement to reliably describe the linear dependence, which is the most important in the case of Ti variation with PF10.7 and also to include possible nonlinearity as a modulation of the linear dependence. In each bin on the local time-latitude grid both parts are determined consecutively as follows: The linear part is determined first by a "robust" fitting technique (e.g., [36]) and then the quadratic part is determined from the residuals by a least square fitting technique. This design of the $T i_{\text {solact }}$ (invdip, MLT, PF10.7) term allows better eliminate cases with possible fitting problems compared to if only the quadratic one is used mainly due to possible presence of outliers. Thus, an expansion of the obtained coefficients by spherical harmonics converges better and backward reconstruction of the whole $T i_{\text {base }}$ term is more accurate. Last but not least, if after the model is built and later the quadratic term in the model needs to be excluded at some anchor altitude (e.g., a linear dependence can be assumed mainly at altitudes of 350 and $430 \mathrm{~km}$ ), this can be easily solved in the program by multiplying this term by zero without having to recalculate the coefficients. Thus, we can use the same formalism in all altitudes which significantly simplifies the resulting program code. The derived coefficients $a_{\text {lin }}, b_{\text {lin }}, a_{q u a}, b_{q u a}, c_{q u a}$ in each bin are expanded as functions of invdip and 
MLT using the same approach as for the Ti base model, i.e., using the expansion according to the Equation (1), but instead of $T i_{\text {base }}$ we put $a_{\text {lin }}$, or $b_{\text {lin }}$, or $a_{q u a}$, or $b_{\text {qua }}$, or $c_{q u a}$.

To obtain Ti for a given day of year (DOY), an interpolation between sub-models for individual seasons using the harmonic functions are employed.

For each altitude and season the whole model consists of 81 coefficients for the base model and $81 \times 5$ coefficients for the solar activity term. For two unique seasons (the December solstice is mirror-reversed June solstice with respect to the dip equator and vice versa) and four altitudes, we need $(81+81 \times 5) \times 2 \times 4=3888$ coefficients in total.

\section{Altitude Profiles}

Once the global models are established for the four fixed altitudes, as described in the section above, they are combined to produce the full altitude profile in the same way as it is done now in the IRI Ti model. This approach is based on the Booker-Epstein formalism (e.g., [14]), which divides the profile into regions of constant gradient with the boundaries given by anchor altitudes. Epstein-step functions are used to transition from one region to the next thus generating a continuous analytical representation of the Ti gradient and integration then results in the final Ti formula.

To describe the ion temperature height profile above $850 \mathrm{~km}$ we adopted the method used in the current IRI ion temperature model [14], i.e., we extrapolate the ion temperature towards higher altitudes using the gradient determined from the section between 600 and $850 \mathrm{~km}$. Next we search for the intersection of this extrapolated Ti profile with the IRI Te profile and then use the intersection height and $\mathrm{Ti}$ at that height as an additional anchor point for the Ti profile. We use a similar approach also at the lower altitudes where we can assume thermal equilibrium with the neutrals and therefore $\mathrm{Ti}=\mathrm{Tn}$. IRI represents $\mathrm{Tn}$ with the help of the NRLMSISE-00 model [16], which is the international standard for Tn. This way we get two more anchor points and hence six anchor altitudes in total (vs. three anchor altitudes in the IRI-2016 Ti model). All these points are then used to construct the entire profile. An example of such a profile is shown in Figure 4.

From this example, we can see that the profile according to the proposed Ti model differs significantly from the profile calculated using the IRI-2016 Ti model. For a large part of the topside, the new Ti model exhibits significantly lower values than the Ti profile according to IRI. The Ti profile from the IRI model merges with the electron temperature profile at an altitude of about $500 \mathrm{~km}$, while the merging height of our new model is close to $2000 \mathrm{~km}$. Note that the data-based Ti values at anchor altitudes of 600 and $850 \mathrm{~km}$ are indeed lower than the corresponding model Te values. 


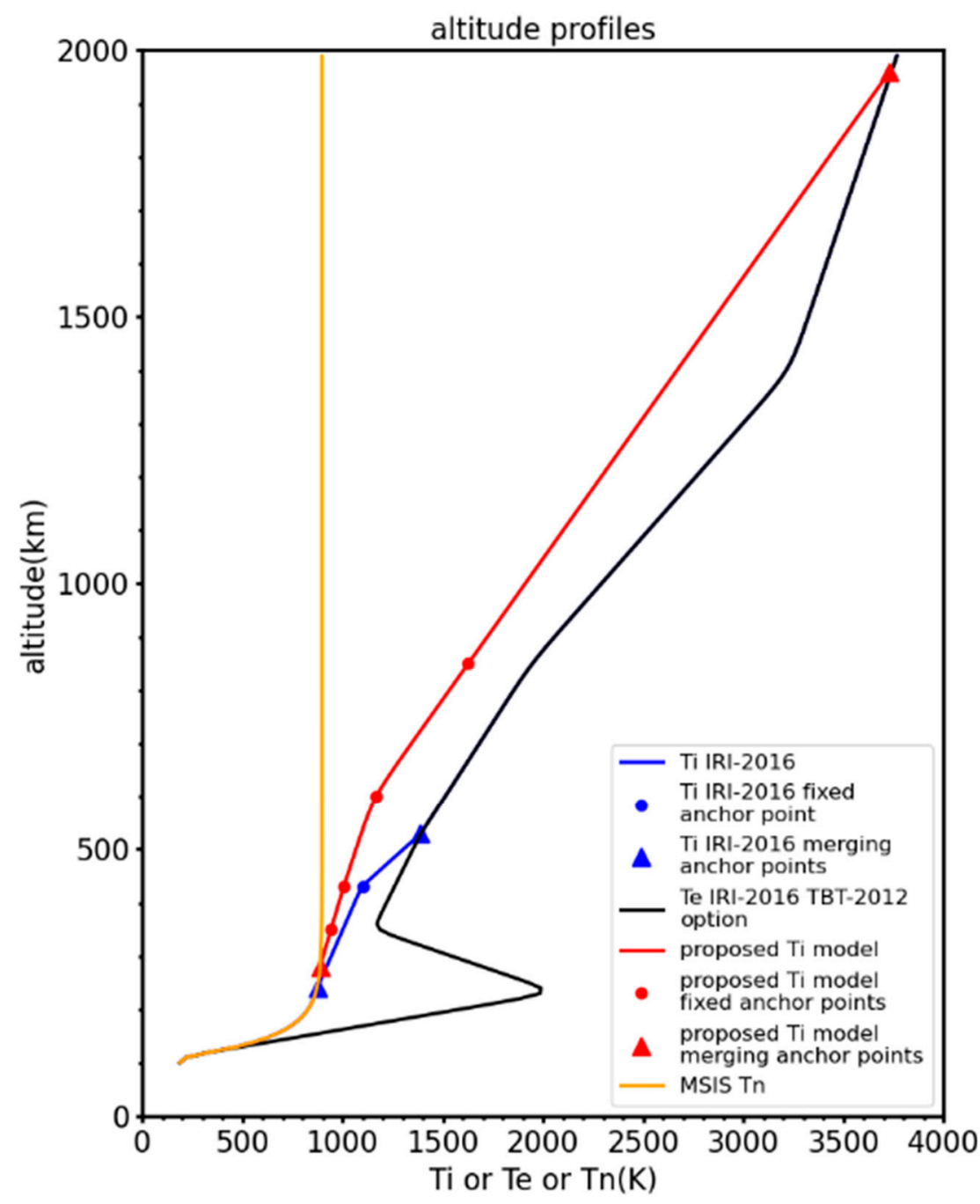

Figure 4. Example of altitude profiles (case for 21 March 2016; PF10.7 = 92; Solar local time $12 \mathrm{~h}$, geographical latitude $=20^{\circ}$; geographical longitude $=0^{\circ}$ ) from the proposed Ti model (red line; 4 red circles represent 4 fixed anchor points with altitudes of 350, 430, 600 and $850 \mathrm{~km}$; 2 red triangles symbolize additional anchor points with variable altitudes-lower one a tangent point on the Tn profile (orange line) and higher one an intersection with the Te profile (black line). The corresponding Ti profile computed from the IRI-2016 model is shown in the blue color (one fixed anchor point at $430 \mathrm{~km}$ height-circle; two anchor points for the connection with Tn and Te-triangles).

\section{Model Results and Examples}

As an example of the model results, we generated global maps for low and high solar activity. Figure 5 shows these contour plots of the whole Ti model for all four fixed anchor altitudes and for both seasons for conditions of solar minimum (calculated for PF10.7 = 70). Figure 6 shows the same but for solar maximum conditions (calculated for PF10.7 = 200). For both extreme levels of solar activity, it can generally be said that the model confirms the well-known fact that the ion temperature increases with altitude and with latitude and that nighttime temperature values are lower than daytime temperature values, which is particularly evident at the equator and low latitudes, and also that the summer hemisphere is warmer than the winter hemisphere. We also note that these extremely different levels of solar activity (solar maximum vs. solar minimum) cause rather strong changes in the ion temperature. Nighttime Ti at $350 \mathrm{~km}$ altitude and at low and mid-latitudes is lower than $800 \mathrm{~K}$ at solar minimum, but higher than $1100 \mathrm{~K}$ at solar maximum. Daytime ion temperature at solar minimum is also very low about $900 \mathrm{~K}$ but at solar maximum reaches $1400 \mathrm{~K}$. This is different from the much smaller changes seen in electron temperature 
(e.g., [31]). Interestingly, at $850 \mathrm{~km}$ altitude in the daytime the relative difference between solar maximum and minimum is much smaller than at lower altitudes ( 350 and $430 \mathrm{~km}$ ). Additionally, even in some cases, the proposed model predicts that Ti is higher during solar minima than maxima. This indicates that ion cooling is strongly dominated by neutral particles at low altitudes, while at $850 \mathrm{~km}$ the cooling by neutral does not play such a role, but heating of ions by electrons is more dominant. Additionally, interesting is the existence of a morning peak in Ti at equatorial latitudes and its development. The morning peak (so-called morning overshoot) is a distinct feature of the electron temperature (e.g., [37,38]). It is dominant at low altitudes and persists up to $850 \mathrm{~km}$. However, at very high altitudes the peak becomes broader and less apparent because of high daytime Te values over the equator (e.g., see contours in [2]). Due to the strong coupling between electrons and ions, a similar peak can be expected also for Ti as the secondary effect of the heating of ions by thermal electrons. The proposed model shows that the morning peak is mainly present at solar minimum and at an altitude of $600 \mathrm{~km}$ (peak maximum about $1700 \mathrm{~K}$ ). At $850 \mathrm{~km}$ the Ti morning peak similarly to the Te peak seems to be less apparent due to increased daytime ion temperature values compared to lower altitudes. At $430 \mathrm{~km}$ altitude and below the peak is very weak, and hardly captured by the model. At solar maximum our Ti model shows that the morning peak is present at $600 \mathrm{~km}$ but its maximum value (about $1500 \mathrm{~K}$ ) is slightly lower than at solar minimum and since the nighttime temperature values are high $(>1100 \mathrm{~K})$ it appears to be much less prominent then at solar minimum. This again confirms that at high solar activity the expanded neutral atmosphere causes increased ion cooling at altitudes below $850 \mathrm{~km}$. 

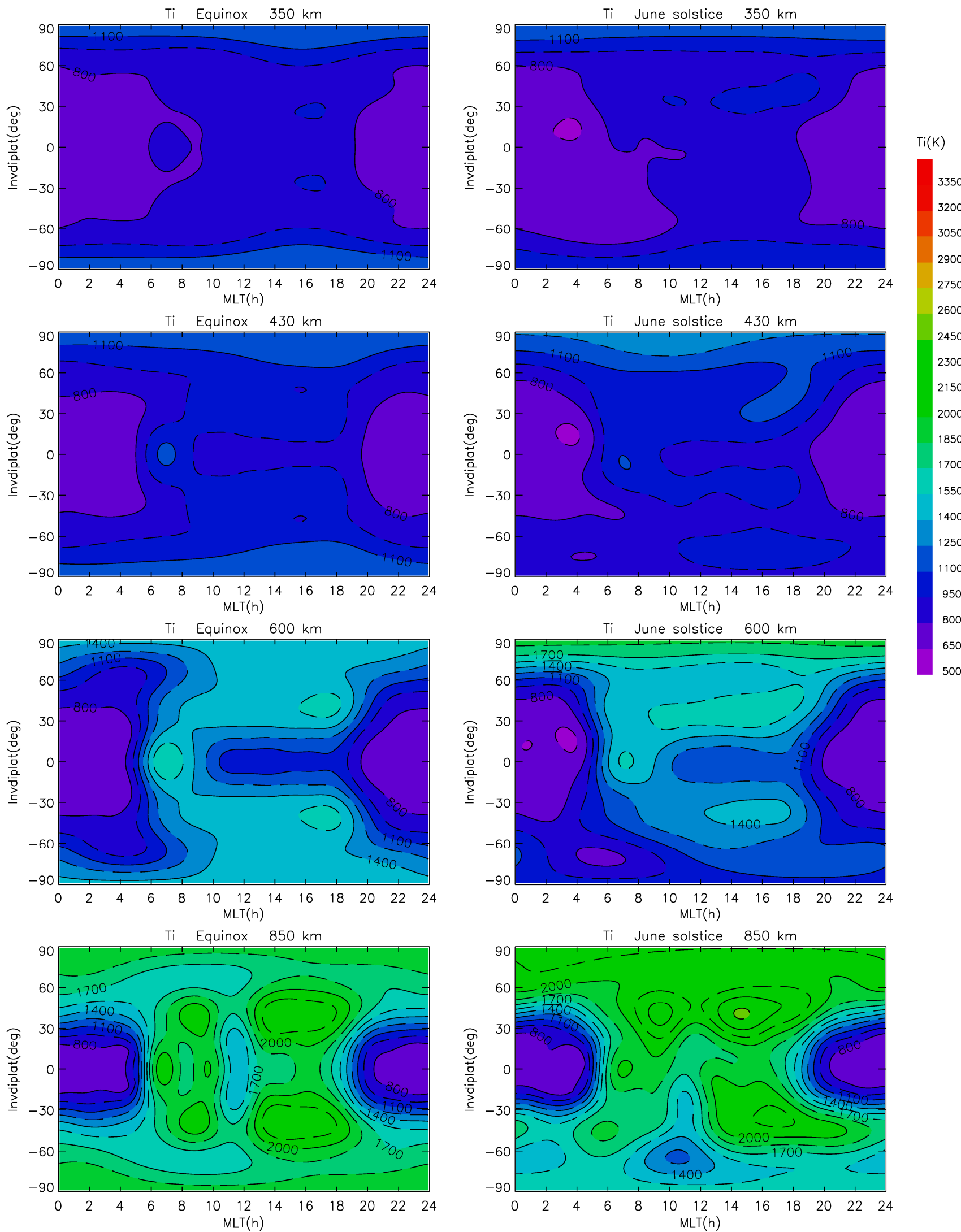

Figure 5. Contour plots of the Ti model for equinox and solstice for the four anchor altitudes during solar minimum $(\mathrm{PF} 10.7=70)$. 

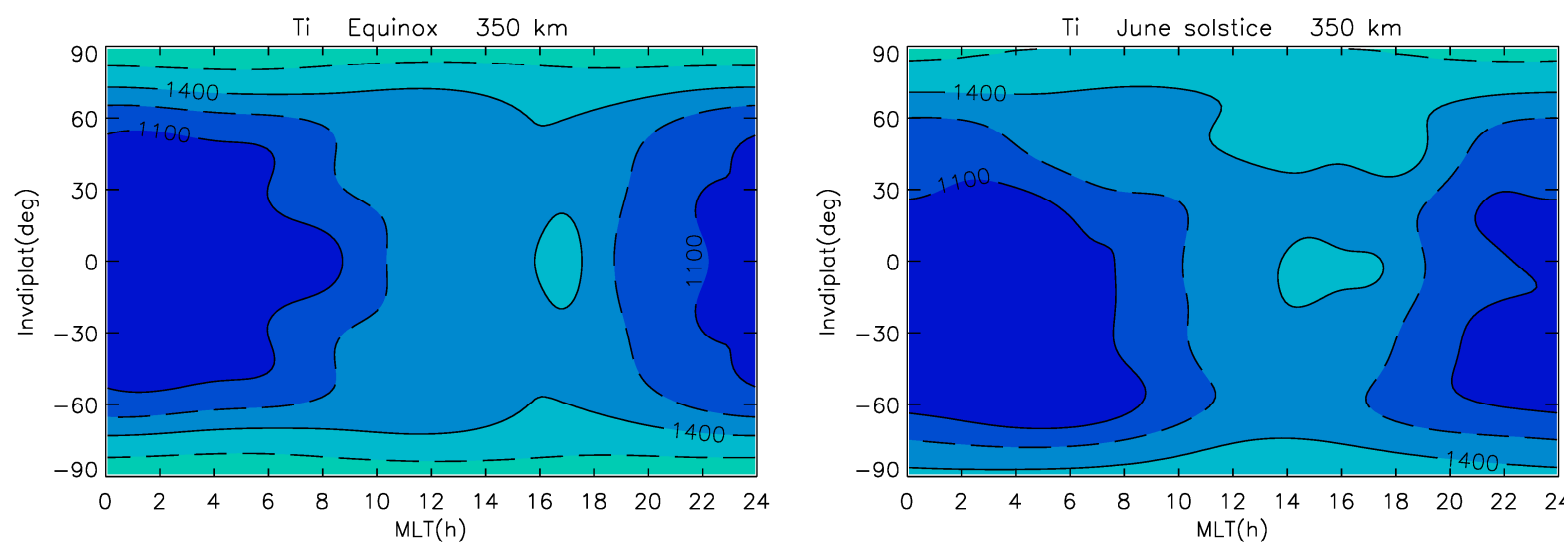

Ti(K)
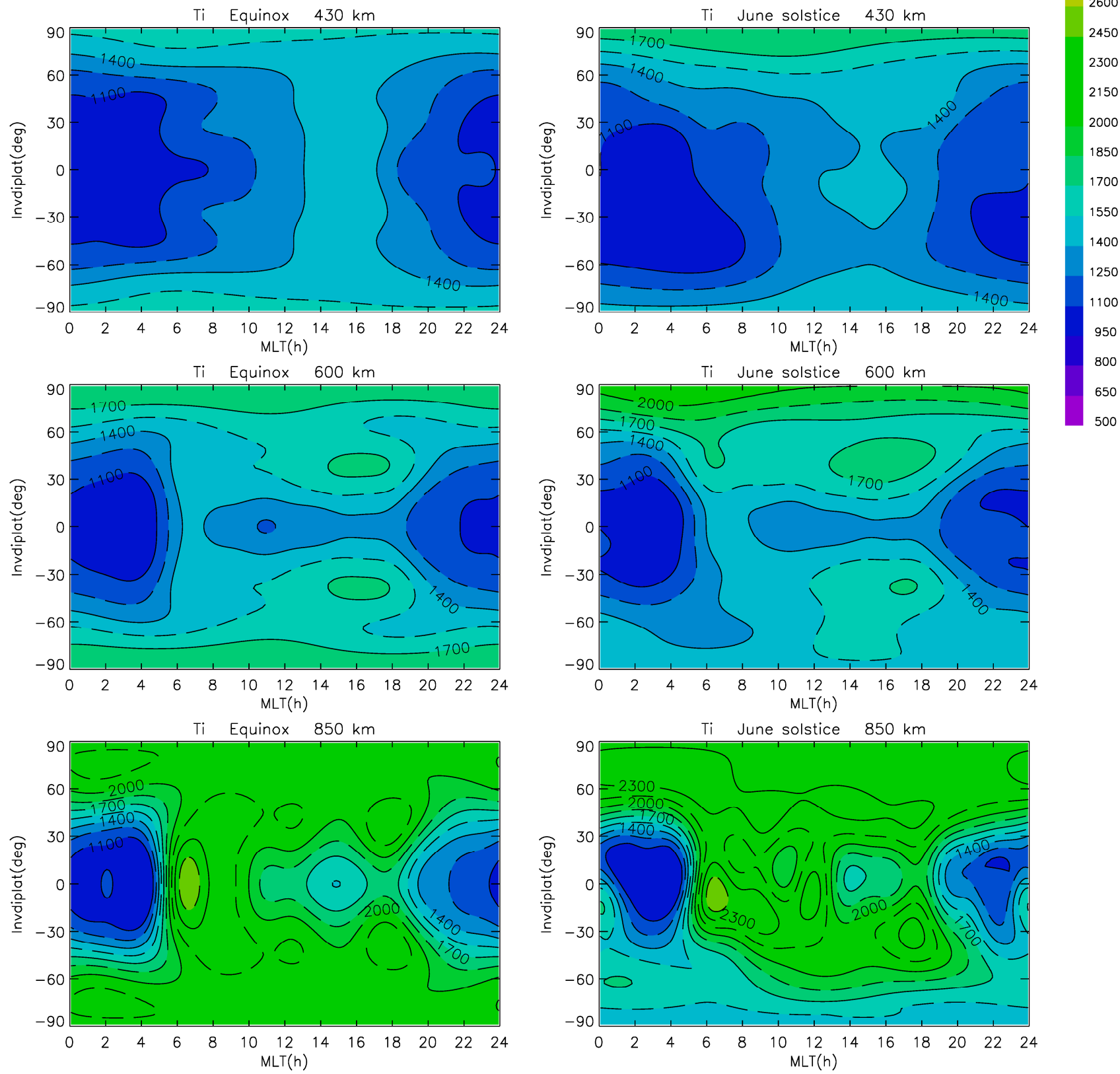

Figure 6. Contour plots of the Ti model for equinox and solstice for four altitude intervals and solar maximum $(\mathrm{PF} 10.7=200)$. 


\section{Comparisons with Data}

\subsection{Comparisons with Jicamarca, Arecibo and Millstone Hill ISR Data}

In this section, we present a comparison of the model values with the incoherent scatter radar data. These are the same data that we had used for determining correction terms for the satellite data with which the model was built (see Section 2.1). Since our comparison is limited to model assessment for equinox and high and low solar activity at the anchor altitudes of 350, 430 and $600 \mathrm{~km}$ a more detailed comparison will be presented in follow-on paper. Figure 7 shows the comparison of our model and of the current IRI model with Jicamarca, Arecibo, and Millstone Hill ISR data for low solar activity with respect to magnetic local time variation. The ISR data were selected for PF10.7 $<95$, from the intervals \pm 30 days centered on 21 March and 23 September, and three altitudes $(350 \pm 35 \mathrm{~km}$, $430 \pm 43 \mathrm{~km}$, and $600 \pm 60 \mathrm{~km}$ ). The data treatment with respect to measurement uncertainty and possible errors was the same as described in the Section 2.1. We binned this data into $0.5 \mathrm{~h}$ of magnetic local time intervals centered at $0.25,0.5, \ldots, 23.75 \mathrm{~h}$. In each bin, medians and upper and lower quartiles were evaluated (black circles and error bars). The proposed Ti model is shown by the red line. Each panel corresponds to a specific altitude and ISR; rows distinguish individual ISRs and columns distinguish different altitudes. Due to the large amount of the ISR data values, we run the proposed Ti model for following conditions; the March equinox (for the September equinox the model gives the same result) and PF10.7 = 82.5 (we found that this value was close to the average PF10.7 for the ISR data satisfying PF10.7 <95). For the IRI-2016 Ti model (shown by the blue line), we searched for such an equinox since 1970 and its close vicinity ( \pm 1 day) for which PF10.7 $=82.5 \pm 2$ s.f.u. because the primary input to the IRI model is the date. To better assess ion temperature variations, we also included Tn values calculated by the IRI code (orange line). Overall, the plots show that the newly proposed Ti model expresses the main features of the diurnal variation of Ti observed by the ISRs. Deviations from the medians are mostly within the variance given by the interquartile range.

For the magnetic equator (Jicamarca-first row) the newly proposed Ti model captures the morning peak quite well, as shown by the ISR data, especially at $600 \mathrm{~km}$ altitude contrary to the current IRI model. Evidence that IRI does not include the morning peak was also presented by Coley et al. [39] and Rana et al. [40]. Some underestimation of the peak amplitude by the model, especially at $430 \mathrm{~km}$, can be due to limitations in the model's temporal resolution. The IRI Ti model shows reasonably good agreement with Jicamarca ISR data at $350 \mathrm{~km}$ altitude, but significant differences at $600 \mathrm{~km}$ overestimating Ti in the daytime and underestimating it in the morning peak. For all three altitudes IRI predicts a nighttime peak at around $2.5 \mathrm{~h}$ MLT that is not observed by the Jicamarca ISR. Ti at the equator is close to Tn at 350 and $430 \mathrm{~km}$ altitude, except for the morning increase where heating of ions by hotter electrons plays a role. At an altitude of $600 \mathrm{~km}$, there is also a noticeable difference between $\mathrm{Tn}$ and Ti during the day.

At low mid-latitudes (Arecibo-middle row), well away from the equator, the proposed Ti model agrees with the ISR data quite well contrary to the IRI Ti model, that tends to overestimate the ISR data. Interestingly, the morning peak in Ti is no longer observed in the data. The ion temperature can be considered close to Tn at an altitude of $350 \mathrm{~km}$, but above this altitude this is only valid at nighttime.

Going even further away from the equator, at high mid-latitudes (Millstone Hill) an even greater difference between the IRI Ti model and the data is evident, while the newly proposed Ti model expresses the diurnal variation observed by the ISR very well. The IRI Ti model at these latitudes has the worst performance of all three latitude zones. At the two lower altitudes, the IRI ion temperature is almost constant throughout the day and night. Comparison with Tn shows that Ti is significantly higher than Tn even at nighttime. 

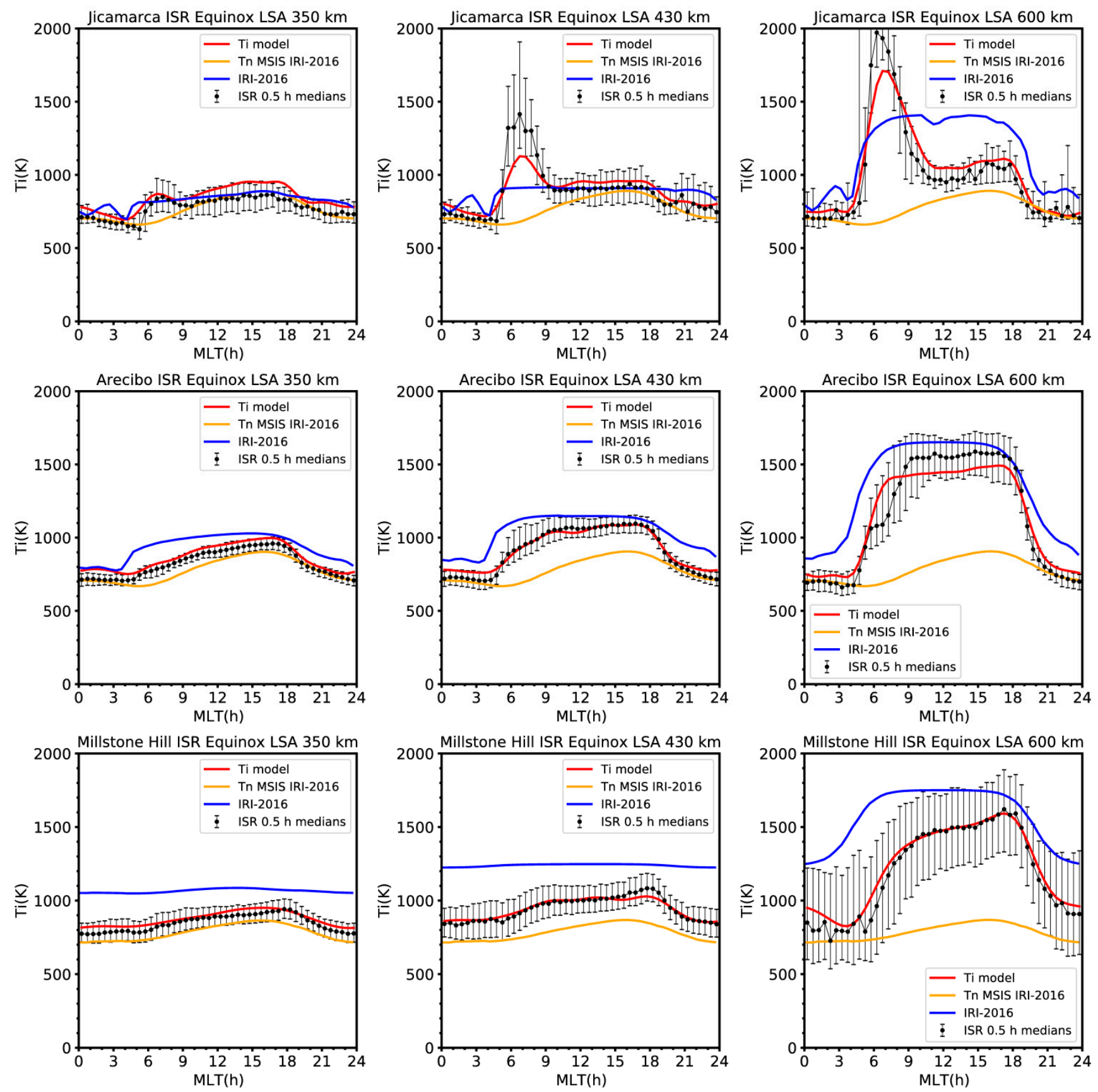

Figure 7. Local time variation of Ti for low solar activity (PF10.7 = 82.5) from the three ISRs (black circles-medians, error bars—upper/lower quartile; Jicamarca-upper row, Arecibo-middle row, Millstone Hill—lower row) and for three altitudes (350 km-left column, $430 \mathrm{~km}$-middle column, $600 \mathrm{~km}$-right column). Included is the proposed Ti model (red line), the IRI-2016 Ti model (blue line), and Tn from the IRI-2016/NRLMSISE-00 model (orange line).

Figure 8 shows our comparison for high solar activity. The ISR data were selected for $180<$ PF10.7 $<220$ and thus the proposed Ti model was run for PF10.7 = 200 and IRI was calculated for an equinoctial day that meets this condition. As in the case of low solar activity, the proposed Ti model again agrees with the ISR data quite well. Ti data from the Jicamarca ISR show a surprisingly large scatter especially before noon, and data are completely missing during the afternoon and until sunset. The IRI Ti model at the equator again shows a good agreement at $350 \mathrm{~km}$ and $430 \mathrm{~km}$. Different from the low solar activity case the Ti morning peak seems to be absent at 350 and $430 \mathrm{~km}$ at high solar activity. 

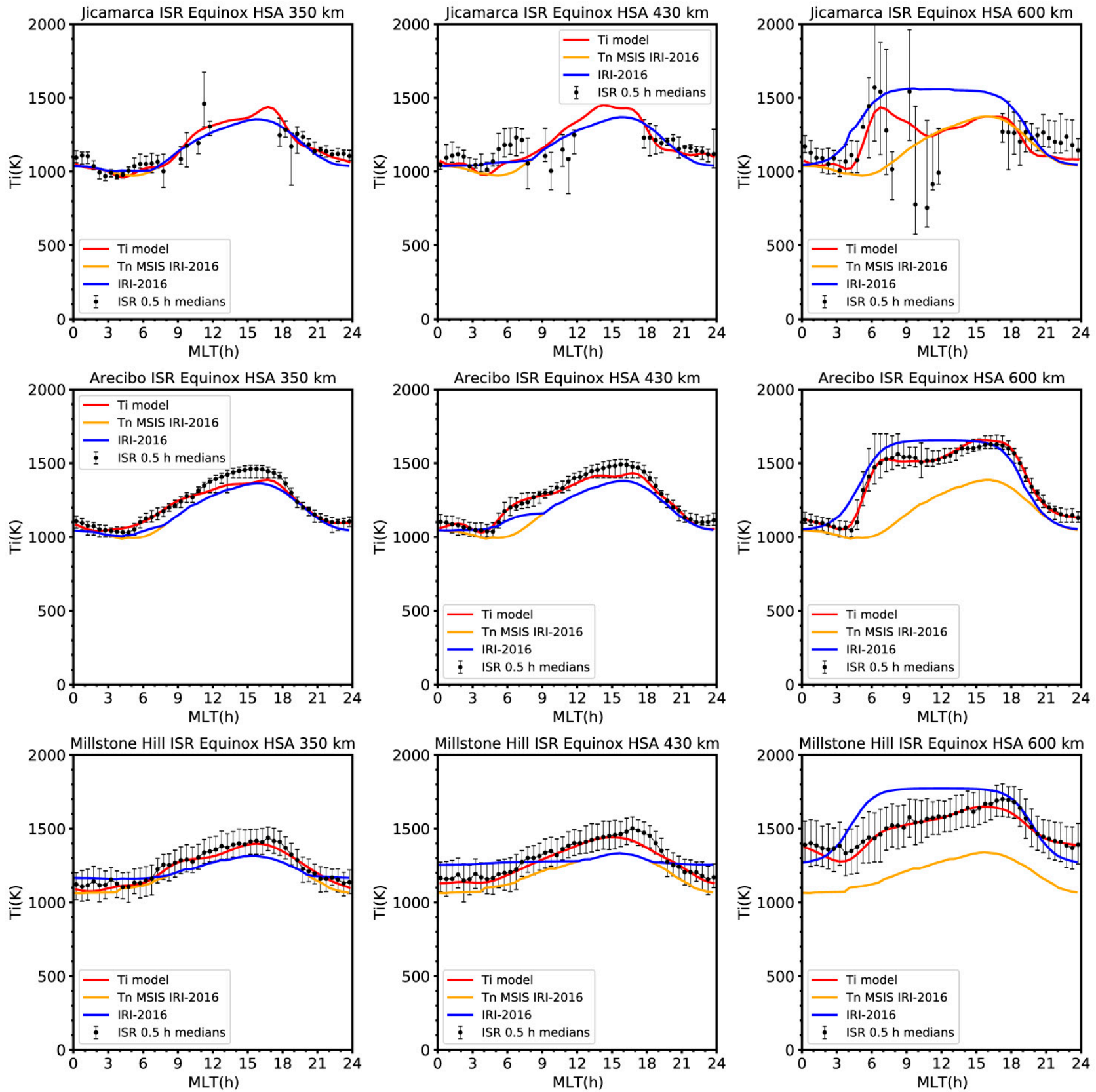

Figure 8. The same as Figure 7, but for high solar activity $($ PF10.7 = 200).

At an altitude of $600 \mathrm{~km}$, the proposed Ti model suggests the presence of a peak with maximum between 6 and $7 \mathrm{~h}$ MLT, but it is much less pronounced than at low solar activity and is difficult to identify in the ISR data due to the large data scatter. With the exception of dawn, Ti appears to be strongly coupled with Tn at the geomagnetic equator at all three altitudes.

At Arecibo, the proposed Ti model tends to somewhat underestimate the measurements at the afternoon Ti maximum for both lower altitudes. The IRI Ti model underestimates the ISR observations, contrary to the low solar activity case at the same location (Figure 7). The IRI values appear to be elevated by Tn at daytime because they are constrained by the condition $\mathrm{Ti} \geq \mathrm{Tn}$ (blue line overlays the orange line). At $600 \mathrm{~km}$ altitude, the Ti observations from the Arecibo ISR exhibit two maxima, which seem to be related to after-dawn and pre-dusk effects, and these are well captured by our Ti model. The IRI Ti model, on the other hand, does not reproduce this variation and shows a flat daytime vari- 
ation instead. We also note that daytime Ti at Arecibo at high solar activity is significantly higher than Tn, most likely due to the increased heat flux from the plasmasphere.

Finally, our comparison with the Millstone Hill ISR observations shows that the proposed Ti model fits the data exceptionally well, while the IRI-2016 model only does well for the lowest altitude, at $430 \mathrm{~km}$, and $600 \mathrm{~km}$ it shows a mixed performance, partially underestimating and partially overestimating the observational data and again, Ti is higher than $\mathrm{Tn}$ at an altitude of $430 \mathrm{~km}$ and above.

\subsection{Comparisons with Kharkiv ISR Ti Data}

For comparison with the data that were used neither for model built nor for data correction, we took advantage of Kharkiv ISR measurements. The Kharkiv incoherent scatter radar, its capabilities, and observational results were described by Kotov et al. [41-44]. The Kharkiv ISR is located in Ukraine near the city of Kharkiv at geographical latitude $49.6^{\circ} \mathrm{N}$ and geographical longitude $36.3^{\circ} \mathrm{E}$, which corresponds to invdip $\approx 47^{\circ}$ and thus represents a region between the Arecibo and Millstone Hill ISRs, which are all in the Americas longitude sector. A limited amount of data covering periods of low and medium solar activity from several recent measurement campaigns was available for this study and is listed in Table 4.

Table 4. Kharkiv ISR Ti measurements intervals for the equinoxes.

\begin{tabular}{cccc}
\hline Month & Day Range & Year & $\overline{\text { PF10.7 }}$ \\
\hline October & $28-30$ & 2004 & 119 \\
September & $20-22$ & 2006 & 75 \\
September & $24-27$ & 2007 & 67 \\
September & $23-24$ & 2008 & 68 \\
September-October & $29-01$ & 2009 & 71 \\
September & $20-22$ & 2010 & 82 \\
September & $25-27$ & 2012 & 128 \\
March & $19-21$ & 2013 & 111 \\
September & $24-26$ & 2013 & 115 \\
March & $28-29$ & 2018 & 69 \\
\hline
\end{tabular}

Again, we limited our comparison to the equinoxes. The comparison was made for an altitude of $400 \mathrm{~km}$, which corresponds to the position between the lowest and the second lowest anchor point of the proposed Ti model. Thus, we can also check how good the interpolation in height is using Booker profiles. Figure 9 shows the comparison of the proposed Ti model (red line), IRI-2016 Ti model (blue line) and Kharkiv data (black line, grey dots-individual measurements). In this comparison the model values were calculated exactly for each ISR measurement. Then, we calculated $1 \mathrm{~h}$ medians and the upper and lower quartiles, as in the case of the measured data. From both panels we can see that the proposed Ti model fits the data well for most MLTs, while the IRI model overestimates the measurements for all times. We would also like to note that, due to the limited amount of data (Table 4), the plot shown cannot be considered as fully representative of the climatological MLT pattern of Ti. Therefore, we computed the model values for each measurement and then we calculated medians from them. The errors bars determined from calculated values of both models are very small, hardly visible on the plots. This suggests that other dependencies, e.g., seasonal, etc., are not mixed in the data. The overestimation by IRI is consistent with the results of the comparison with the Millstone Hill data for low solar activity (Figure 6, left and middle panels, bottom row). 

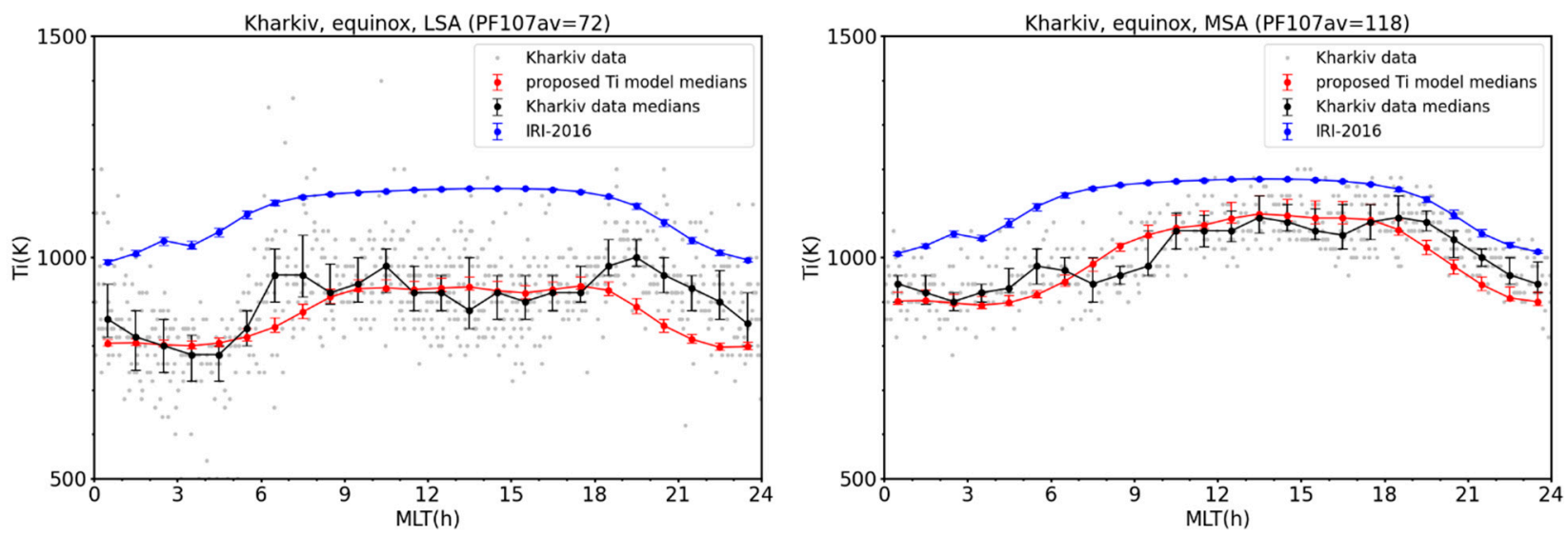

Figure 9. Local time variation of Kharkiv Ti data (grey points—individual measurements; black circles—medians in $1 \mathrm{~h}$ wide MLT bins; error bars represent upper and lower quartiles), corresponding medians and lower/upper quartiles from the proposed Ti and IRI-2016 models (red and blue, respectively). The left panel represents low solar activity (LSA) and the right panel represents medium solar activity (MSA).

\section{Discussion and Conclusions}

In this paper, we present a newly proposed global empirical ion temperature (Ti) model that is an improvement over the option for Ti included in the IRI-2016 model, which is basically unchanged since it was introduced in the IRI-1990 version of the model [14]. The new model is based on data from a large Ti database compiled by the authors from almost all available Ti measurements by satellites from the late 1960s to the present. The advantage of satellite measurements for the construction of the global model lies in the coverage of all latitudes compared to the incoherent scatter radars (ISRs), of which there are only a few worldwide. However, in this study we used data from both. The ISR data helped us to intercalibrate satellite measurements because data from individual satellite missions often show unacceptable differences when compared with data from other satellites for the same conditions, probably due to differences in the design of individual instruments, their electronics, etc. We made this correction by comparing the median of data binned in altitude, latitude, local time, and solar activity for each satellite and ISR. As we used geomagnetic coordinate (invdip) we neglected the influence of longitude, which can be considered a third-order influence parameter, and thus this version of the model neglects longitudinal differences. We have also neglected the effect of geomagnetic activity, whose influence on the ion temperature at least at low and mid-latitudes on a climatological scale can also be considered a third-order effect. Both effects excluded from the space of modelling parameters for the construction of our model might be included in some future version as an additional additive term based on modelling of the corresponding residuals. The proposed corrections for individual satellites, which we used to intercalibrate the data need to be further investigated specifically for case studies that use only part of a specific satellite data set. The obtained correction equations in Table 2 show that the RPA data tend to overestimate Ti relative to the ISR data in most cases. The overestimation is in general moderate, but in some cases can be as high as $30 \%$ or more (Figure 2). However, a discussion of the causes is beyond the scope of this study. The analysis of systematic errors in temperature from satellite RPAs has been dealt with by, e.g., Davidson et al. [45] and Klenzing et al. [46]. Our modelling approach is based on spherical harmonics up to 8 th order, which provided good agreement with the data both in latitude (invdip) and local time (MLT) and is different from the IRI model, which is based on just one anchor point, while our model uses four anchor points providing a more detailed representation of the altitudinal structure of the ionospheric Ti profile. The height profile is then constructed using the Booker approach as explained in Section 4, whereby Tn is used as a constraint from below and Te as a constraint from above, as employed in the current IRI model. Compared to the current IRI Ti model the new model is able to pick up much more of the 
altitudinal, latitudinal, and diurnal structure seen in measurements of the ionospheric ion temperature because of the increased number of anchor points and the high order in the spherical harmonics used to describe variations with MLT and invdip. Comparison with the data (Figures 7-9) shows a significant improvement over the IRI model, which shows systematic limitations, especially at mid-latitudes towards the poles and at higher altitudes $(\sim 600 \mathrm{~km})$. The main results of this paper are as follows:

- Correction factors were determined for a large number satellite Ti measurements based on comparisons with ISR data.

- A global ion temperature model was developed based on a database of these corrected satellite Ti measurements.

- $\quad$ The model represents the climatology of the ion temperature at altitudes from 350 to $850 \mathrm{~km}$ using global sub-models at four fixed altitudes.

- Below an altitude of $350 \mathrm{~km}$, the model uses a connection to Tn and above $850 \mathrm{~km}$ a connection to Te.

- $\quad$ The dependence on solar activity (PF10.7 as a proxy index) is expressed as an additive term that includes both linear and quadratic dependencies.

- Comparison with ISR data (Jicamarca, Arecibo, Millstone Hill, and Kharkiv) shows that the model describes the diurnal variation quite well for both low and high solar activity at different altitudes and latitudes.

- Different from the current IRI model the new model captures the morning peak and its dependence on solar activity and altitude, with the peak being most pronounced during periods of low solar activity and at $\sim 600 \mathrm{~km}$ altitude.

- A comparison of the IRI and our new model with the data used in the model developments highlights fundamental flaws of the current IRI Ti model, while the new model is fully consistent with this large data base and is therefore an appropriate alternative to the current model.

- Future developments could include an extension to include third order dependencies such as magnetic activity or longitude and the use of data from more recent missions (COSMIC-2), and possibly fully integrate ISR data into the model including data from ISRs not yet included like EISCAT, Pokker Flat, etc.

- $\quad$ The model is available as a subroutine in FORTRAN 77.

Author Contributions: V.T. and D.B. were principal investigators of the Czech-US collaborative project. Conceptualization, V.T. and D.B.; data processing and modelling, V.T.; writing-original draft preparation and editing, V.T., D.B., D.K. and M.S.; the IRI model development, D.B.; Kharkiv ISR data processing, D.K., M.S.; satellite data check, V.T. and L.T.; interpretation of results, V.T., D.B., D.K., M.S. and L.T. All authors have read and agreed to the published version of the manuscript.

Funding: V.T. was supported by grant LTAUSA17100 by the Ministry of Education, Youth and Sports of the Czech Republic. D.K. was supported by the Ministry of Education and Science of Ukraine. M.S. were supported by the project 0119U100032 “Investigations of long-term changes of the plasmasphere: new results for security into the space and on Earth" funded by the Ministry of Education and Science of Ukraine.

Institutional Review Board Statement: Not applicable.

Informed Consent Statement: Not applicable.

Data Availability Statement: The data sets used here are publicly available. Satellite data are available from NASA's Space Physics Data Facility (SPDF), accessed on 7 November 2019, from the Madrigal service (DMSP data) (http: / / cedar.openmadrigal.org, accessed on 15 June 2018), and from icon.ssl.berkeley.edu, accessed on 29 June 2020. The ISR data are available from the Madrigal service (http: / / cedar.openmadrigal.org, accessed on 13 May 2020) and from the Institute of ionosphere Database (http://database.iion.org.ua/, accessed on 21 May 2018). The International Reference Ionosphere model is available on www.irimodel.org, accessed on 3 April 2020. The new Ti model described in this paper is available on GitHub (https:/ / github.com/vtrufacascz/Ti_model, uploaded on 25 June 2021). 
Acknowledgments: We are grateful to NASA's Space Physics Data Facility (SPDF) for providing the satellite Ti data from OGO-6, AEROS A, AEROS B, AE-C, AE-D, AE-E, DE-2, San Marco, ROCSAT-1 and C/NOFS. The full recovery of the OGO-6, AEROS A and AEROS B Ti data required an additional processing due to the old IBM binary format using a program developed with the help of J. Klas a former employee of the Institute of Atmospheric Physic of the Czech Academy of Sciences. We would like also to acknowledge the Madrigal service) for providing access to the ISR data and DMSP SSIES-2 F11-F15 data and M. Hairston et al. from University of Texas at Dallas, who provided this data (labeled "UT DMSP with quality flags") to the Madrigal service. We also thank the ICON team (icon.ssl.berkeley.edu, accessed on 29 June 2020) and the William B. Hanson Center for Space Sciences at UT Dallas for making the ICON IVM Ti data available and to P. K. Bhuyan and J. Smilauer for providing data from the SROSS C2 and IK-24 satellites respectively. We are also grateful to S.-R. Zhang and B. Rideout for their help with downloading the ISR data. V.T. appreciates useful discussion with Y. Yamazaki (GFZ Potsdam) regarding Ti at low and equatorial latitudes using the TIE-GCM model.

Conflicts of Interest: The authors declare no conflict of interest.

\section{References}

1. Banks, P.M.; Kockarts, G. Aeronomy; Academic Press: New York, NY, USA, 1973; p. 2.

2. Truhlik, V.; Bilitza, D.; Triskova, L. A new global empirical model of the electron temperature with the inclusion of the solar activity variations for IRI. Earth Planets Space 2012, 64, 531-543. [CrossRef]

3. Brace, L.H.; Theis, R.F. Global Empirical-Models of Ionospheric Electron-Temperature in the Upper F-Region and Plasmasphere Based on Insitu Measurements from the Atmosphere Explorer-C, Isis-1 and Isis-2 Satellites. J. Atmos. Terr. Phys. 1981, 43, 1317-1343. [CrossRef]

4. Bilitza, D.; Brace, L.H.; Theis, R.F. Modelling of ionospheric temperature profiles. Adv. Space Res. 1985, 5, 53-58. [CrossRef]

5. Bilitza, D.; Truhlik, V.; Richards, P.; Abe, T.; Triskova, L. Solar cycle variations of mid-latitude electron density and temperature: Satellite measurements and model calculations. Adv. Space Res. 2007, 39, 779-789. [CrossRef]

6. Schunk, R.W.; Nagy, A.F. Electron Temperatures in F-Region of Ionosphere-Theory and Observations. Rev. Geophys. 1978, 16, 355-399. [CrossRef]

7. Mott-Smith, H.M.; Langmuir, I. The theory of collectors in gaseous discharges. Phys. Rev. 1926, 28, 727. [CrossRef]

8. Knudsen, W.C. Evaluation and Demonstration of Use of Retarding Potential Analyzers for Measuring Several Ionospheric Quantities. J. Geophys Res. 1966, 71, 4669-4678. [CrossRef]

9. Knudsen, D.; Burchill, J.; Buchert, S.; Eriksson, A.; Gill, R.; Wahlund, J.E.; Åhlén, L.; Smith, M.; Moffat, B. Thermal ion imagers and Langmuir probes in the Swarm electric field instruments. J. Geophys. Res. Space Phys. 2017, 122, 2655-2673. [CrossRef]

10. Bilitza, D. Electron and ion temperature data for ionospheric modelling. Adv. Space Res. 1991, 11, 139-148. [CrossRef]

11. Schunk, R.W.; Nagy, A.F. Ionospheres of the Terrestrial Planets. Rev. Geophys. 1980, 18, 813-852. [CrossRef]

12. Hsu, C.T.; Heelis, R.A. Measurement of Individual H+ and O+ Ion Temperatures in the Topside Ionosphere. J. Geophys. Res. Space Phys. 2018, 123, 1525-1533. [CrossRef]

13. Bilitza, D.; Altadill, D.; Truhlik, V.; Shubin, V.; Galkin, I.; Reinisch, B.; Huang, X. International Reference Ionosphere 2016: From ionospheric climate to real-time weather predictions. Space Weather 2017, 15, 418-429. [CrossRef]

14. Bilitza, D. International Reference Ionosphere 1990; Report 90-22; National Space Science Data Center: Greenbelt, MD, USA, 1990.

15. Pignalberi, A.; Aksonova, K.D.; Zhang, S.-R.; Truhlik, V.; Gurram, P.; Pavlou, C. Climatological study of the ion temperature in the ionosphere as recorded by Millstone Hill incoherent scatter radar and comparison with the IRI model. Adv. Space Res. 2021, 68, 2186-2203. [CrossRef]

16. Picone, J.M.; Hedin, A.E.; Drob, D.P.; Aikin, A.C. NRLMSISE-00 empirical model of the atmosphere: Statistical comparisons and scientific issues. J. Geophys. Res. Space Phys. 2002, 107, 1468-1483. [CrossRef]

17. Heelis, R.; Hanson, W. Measurements of thermal ion drift velocity and temperature using planar sensors. Geophys. Monogr. Am. Geophys. Union 1998, 102, 61-72.

18. Hanson, W.B.; Sanatani, S.; Zuccaro, D.; Flowerday, T.W. Plasma Measurements with Retarding Potential Analyzer on Ogo-6. J. Geophys. Res. 1970, 75, 5483-5501. [CrossRef]

19. Spenner, K.; Dumbs, A. Retarding Potential Analyzer on Aeros-B. Z. Geophys. 1974, 40, 585-592.

20. Hanson, W.B.; Zuccaro, D.R.; Lippincott, C.R.; Sanatani, S. Retarding-Potential Analyzer on Atmosphere Explorer. Radio Sci. 1973, 8, 333-339. [CrossRef]

21. Hanson, W.; Heelis, R.; Power, R.; Lippincott, C.; Zuccaro, D.; Holt, B.; Harmon, L.; Sanatani, S. The retarding potential analyzer for Dynamics Explorer-B. Space Sci. Instrum. 1981, 5, 503-510.

22. Broglio, L.; Ponzi, U.; Arduini, C. The San Marco 5 mission. Adv. Space Res. 1993, 13, 165-184. [CrossRef]

23. Afonin, V.V.; Smirnova, N.F. Optimization of Complex Experiment on Measurement of the Cold Plasma Parameters; Space Research Institute: Moscow, Russia, 1990; pp. 1-21. 
24. Rich, F. Users Guide for the Topside Ionospheric Plasma Monitor (SSIES, SSIES-2 and SSIES-3) on Spacecraft of the Defense Meteorological Satellite Program., Volume 1: Technical Description; PHILLIPS LABORATORY, Hanscom Air Force Base: Bedford, MA, USA, 1994.

25. Garg, S.; Anand, J.; Bahl, M.; Subrahmanyam, P.; Rajput, S.; Maini, H.; Chopra, P.; John, T.; Singhal, S.; Singh, V.; et al. RPA Aeronomy Experiment Onboard the Indian Satellite SROSS-C2-Some Important Aspects of the Payload and Satellite. Indian J. Radio Space Phys. 2003, 32, 5-15.

26. Borgohain, A.; Bhuyan, P.K. Solar cycle variation of ion densities measured by SROSS C2 and FORMOSAT-1 over Indian low and equatorial latitudes. J. Geophys. Res. Space Phys. 2010, 115, 1-13. [CrossRef]

27. Su, S.-Y.; Yeh, H.C.; Heelis, R.A.; Wu, J.-M.; Yang, S.C.; Lee, L.-F.; Chen, H.L. The ROCSAT-1 IPEI preliminary results: Low-latitude ionospheric plasma and flow variations. Terr. Atmos. Ocean Sci. 1999, 10, 787-804. [CrossRef]

28. Chao, C.K.; Su, S.Y.; Yeh, H.C. Ion temperature variation observed by ROCSAT-1 satellite in the afternoon sector and its comparison with IRI-2001 model. Adv. Space Res. 2006, 37, 879-884. [CrossRef]

29. de La Beaujardière, O. C/NOFS: A mission to forecast scintillations. J. Atmos. Sol. Terr. Phys. 2004, 66, 1573-1591. [CrossRef]

30. Heelis, R.A.; Stoneback, R.A.; Perdue, M.D.; Depew, M.D.; Morgan, W.A.; Mankey, M.W.; Lippincott, C.R.; Harmon, L.L.; Holt, B.J. Ion Velocity Measurements for the Ionospheric Connections Explorer. Space Sci. Rev. 2017, 212, 615-629. [CrossRef]

31. Truhlik, V.; Bilitza, D.; Triskova, L. Latitudinal variation of the topside electron temperature at different levels of solar activity. Adv. Space Res. 2009, 44, 693-700. [CrossRef]

32. Richards, P.G.; Fennelly, J.A.; Torr, D.G. Euvac-A Solar Euv Flux Model for Aeronomic Calculations. J. Geophys. Res. Space Phys. 1994, 99, 8981-8992. [CrossRef]

33. Truhlik, V.; Triskova, L.; Smilauer, J.; Afonin, V.V. Global empirical model of electron temperature in the outer ionosphere for period of high solar activity based on data of three intercosmos satellites. Adv. Space Res. Ser. 2000, 25, 163-169. [CrossRef]

34. Truhlik, V.; Triskova, L.; Saxonbergova-Jankovicova, D. Observations of the ion temperature in morning hours in the equatorial topside ionosphere from ICON and other satellites. In Proceedings of the AGU Fall Meeting, San Francisco, CA, USA, 1-17 December 2020. Available online: https: / / agu2020fallmeeting-agu.ipostersessions.com/Default.aspx?s=D7-4D-E6-A7-05-7A-3B09-20-07-14-FC-3E-D4-09-D4 (accessed on 7 December 2020).

35. Martinec, Z. Program to Calculate the Least-Squares Estimates of the Spherical Harmonic Expansion Coefficients of an Equally Angular-Gridded Scalar Field. Comput. Phys. Commun. 1991, 64, 140-148. [CrossRef]

36. Press, W.H.; Teukolsky, S.A.; Vetterling, W.T.; Flannery, B.P. Numerical Recipes in C: The Art of Scientific Computing, 2nd ed.; Cambridge University Press: New York, NY, USA, 1992.

37. Oyama, K.I.; Watanabe, S.; Su, Y.; Takahashi, T.; Hirao, K. Season, local time, and longitude variations of electron temperature at the height of similar to $600 \mathrm{~km}$ in the low latitude region. Adv. Space Res. 1996, 18, 269-278. [CrossRef]

38. Stolle, C.; Liu, H.; Truhlik, V.; Luhr, H.; Richards, P.G. Solar flux variation of the electron temperature morning overshoot in the equatorial F region. J. Geophys. Res. Space Phys. 2011, 116, 1-13. [CrossRef]

39. Coley, W.R.; Heelis, R.A.; Hairston, M.R.; Earle, G.D.; Perdue, M.D.; Power, R.A.; Harmon, L.L.; Holt, B.J.; Lippincott, C.R. Ion temperature and density relationships measured by CINDI from the C/NOFS spacecraft during solar minimum. J. Geophys. Res. Space Phys. 2010, 115, 1-6. [CrossRef]

40. Rana, G.; Bardhan, A.; Sharma, D.K.; Yadav, M.K.; Aggarwal, M.; Dudeja, J. Variations of ion density and temperature as measured by ROCSAT-1satellite over the Indian region and comparison with IRI-2016 model. Ann. Geophys. 2019, 62, 11. [CrossRef]

41. Kotov, D.V.; Richards, P.G.; Bogomaz, O.V.; Chernogor, L.F.; Truhlik, V.; Emelyanov, L.Y.; Chepurnyy, Y.M.; Domnin, I.F. The importance of neutral hydrogen for the maintenance of the midlatitude winter nighttime ionosphere: Evidence from IS observations at Kharkiv, Ukraine, and field line interhemispheric plasma model simulations. J. Geophys. Res. Space Phys. 2016, 121, 7013-7025. [CrossRef]

42. Kotov, D.V.; Richards, P.G.; Truhlik, V.; Bogomaz, O.V.; Shulha, M.O.; Maruyama, N.; Hairston, M.; Miyoshi, Y.; Kasahara, Y.; Kumamoto, A.; et al. Coincident Observations by the Kharkiv IS Radar and Ionosonde, DMSP and Arase (ERG) Satellites, and FLIP Model Simulations: Implications for the NRLMSISE-00 Hydrogen Density, Plasmasphere, and Ionosphere. Geophys. Res. Lett 2018, 45, 8062-8071. [CrossRef]

43. Kotov, D.V.; Richards, P.G.; Truhlik, V.; Maruyama, N.; Fedrizzi, M.; Shulha, M.O.; Bogomaz, O.V.; Lichtenberger, J.; HernandezPajares, M.; Chernogor, L.F.; et al. Weak Magnetic Storms Can Modulate Ionosphere-Plasmasphere Interaction Significantly: Mechanisms and Manifestations at Mid-Latitudes. J. Geophys. Res. Space Phys. 2019, 124, 9665-9675. [CrossRef]

44. Kotov, D.V.; Truhlik, V.; Richards, P.G.; Stankov, S.; Bogomaz, O.V.; Chernogor, L.F.; Domnin, I.F. Night-time light ion transition height behaviour over the Kharkiv (50 degrees N, 36 degrees E) IS radar during the equinoxes of 2006-2010. J. Atmos. Sol. Terr. Phys. 2015, 132, 1-12. [CrossRef]

45. Davidson, R.; Earle, G.; Klenzing, J.; Heelis, R. A numerical study of geometry dependent errors in velocity, temperature, and density measurements from single grid planar retarding potential analyzers. Phys. Plasmas 2010, 17, 082901. [CrossRef]

46. Klenzing, J.; Earle, G.; Heelis, R.; Coley, W. A statistical analysis of systematic errors in temperature and ram velocity estimates from satellite-borne retarding potential analyzers. Phys. Plasmas 2009, 16, 052901. [CrossRef] 